\title{
High Performing Group: Relationship between Group Cohesiveness and Work Performance. A Conceptual Study
}

\author{
Najmiah Bt. Hj. Abdullah \\ Kolej Komuniti Sungai Petani, \\ Kementerian Pendidikan Malaysia \\ Zurina Bt Awang \\ Kolej Komuniti Sungai Petani, \\ Kementerian Pendidikan Malaysia \\ Reezlin Abd Rahman \\ Kolej Komuniti Sungai Petani, \\ Kementerian Pendidikan Malaysia
}

\begin{abstract}
Working in groups generates more diversity output. A successful organizations usually have a high-performance teams to work together. High-performing teams comprise of structured members who are always aware and ready in every job task. In fact, a minimum supervision can be implemented to this team in order to achieve the organization objectives. One of the criteria that contributes to a high performing team is the group cohesiveness. The cohesiveness of the group will make the group members always united and prioritize the group in an effort to complete a job task. Not exaggerate that, each member of the group will do whatever it takes to achieve the final goal of the group. Among the factors that lead to group cohesiveness are through communication, understandable objectives and group member's commitment. To ensure the cohesiveness of the group continues, the management should set the organizational goals, provide a conducive working environment, setting clear the goal, expectations and responsibilities, provide appropriate training and staffing and also empower them to act. In a simple understanding, the higher the cohesion in a group, the greater the performance of the work in an organization.
\end{abstract}

Keywords: High Performance Group, Cohesiveness, Job Performance

\section{INTRODUCTION}

Teamwork provide benefits in terms of diversity of knowledge sharing, brainstorming and ideas as well as friendship and communication among group members. A good teamwork basically come from the high performance team. The High-Performance Team is a group that always gives a positive result towards the achievement of predetermined objectives (Beal, Cohen, Burke, \& McLendon, 2003). The key feature that can be seen in this high-performing group is group cohesiveness, which measures the extent to which members in a group are united in achieving the objectives set (Carron \& Brawley, 2012).

\section{Group Cohesiveness}

\section{LITERATURE REVIEW}

The cohesiveness of the group refers to the tendency of group members to unite while performing a task towards achieving a goal or to meet the emotional needs between members in the group. According to Lott and Lott (1965), personal attraction among members is sufficient to be considered cohesion in the group. In other words, group cohesion exists when members have the same sense of understanding. Based on Castaño, Watts, \& Tekleab, (2013), 
the factors that lead to success of the group cohesiveness were based on; a) Communications that refer to effective communication plays an important role in ensuring the information that is being communicated to each member of the group is upheld and understood. Moreover, through communication, group members can freely interact by giving opinions or suggestions for increasing trust in the group (Greer, 2012); b) Clear and Precise Objective that denotes to the understanding on what goal that group need to accomplish. When the group team members understand the goal, vision and mission of the organizational objectives, each of the team members will strive to achieve the goals that have been set (Drescher, Burlingame, \& Fuhriman, 2012); c) Commitment which explain on with effective communication, together with understood objectives will increase high commitment among the members of the group. Each member must have information about what is expected outcome that have been set. Carron \& Brawley, 2012). Members who clearly comprehend on their roles and duties can work together and try their best in helping each other to cooperate in the group (Carron \& Brawley, 2012).

\section{Management Role in Cohesiveness}

The management is also plays an important role in ensuring the cohesion of the groups in the organization can be established and maintained (Beal et.al, 2003). Although group cohesion is an important factor in determining the effectiveness of the group, but it also need to be supported by management commitment. Among the roles to be played by the management are; a) Goal setting by constructing the objectives of the organization and guideline and also needs to ensure the mission accomplishment is align with the goal setting; b) Working environment which refers to the physical facilities and the condition of the workplace environment that need to be comfortable and conducive to the members to express their opinion or view of the issues or job concerned; c) Setting Clear Expectations and Responsibilities that denotes to setting clear expectations and responsibilities for each members and group target achievement. This is to ensure that members of the group acquire a clear description of their roles and what they need to do. Moreover, the group members also needs to be informed the time period given beside the target expected by the management; d) Power to act that related to giving empowerment to the group in making the decision with monitoring from the management. Besides, the improvement on the decision need to be done when it necessary to align with the initial objectives.

\section{Cohesiveness and Work Performance}

Successful organizations are often supported by effective team with a high level cohesion who tend to commit to achieving organizational objectives and strategies (Carron \& Brawley, 2012). Reaching the high performing group is not a coincidence but it is achieved through the high engagement of trust among members and mutual understanding amongst other members. This can be clarify through figure 1 below that indicated the relationship between Performance relevance and group cohesiveness 


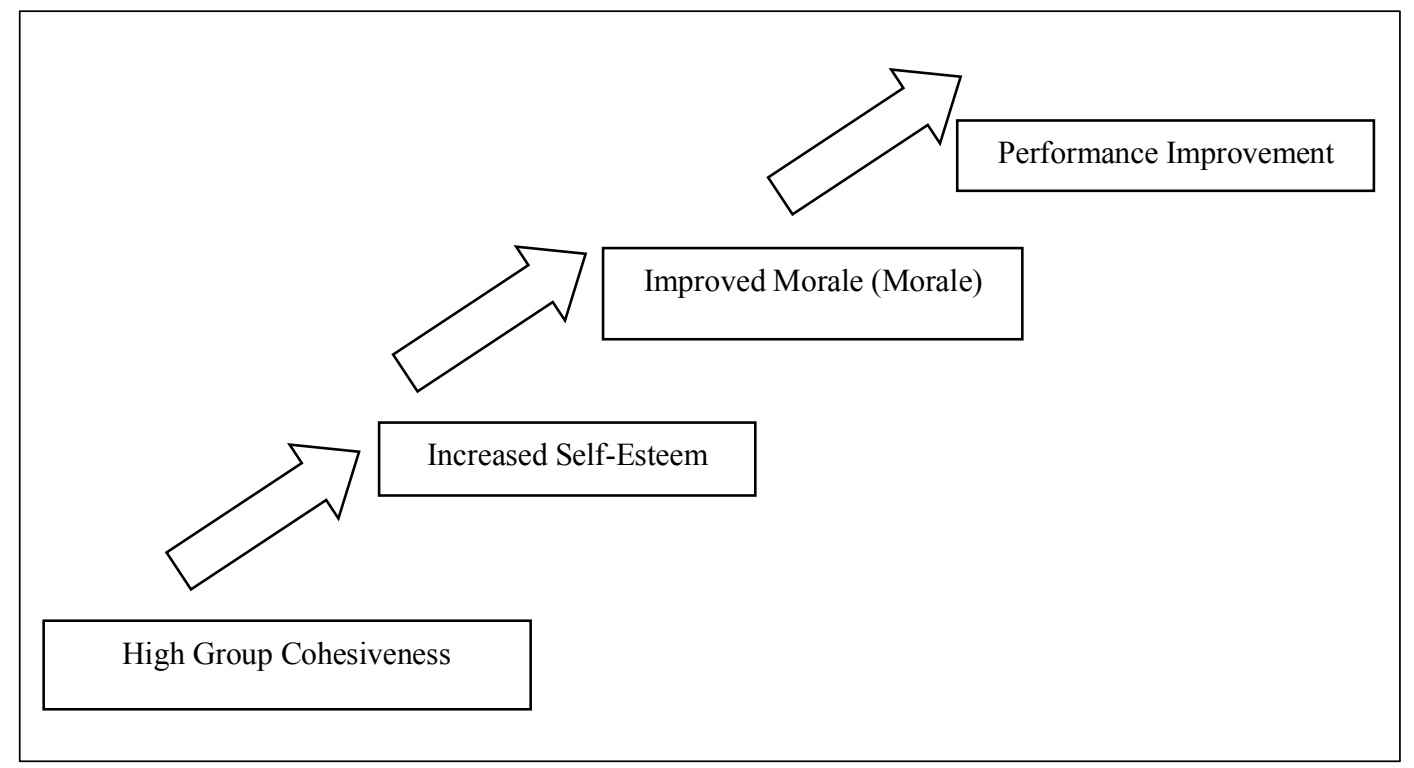

Figure 1: Cohesion and Performance

(Source: High performance Teams: Understanding Team Cohesiveness: https://www.isixsigma.com/implementation/teams/)

\section{CONCLUSION AND RECOMMENDATION}

The group cohesiveness will create a high performing group that significantly giving impact to the organization. The organization unable to operate with only one or two members that require groups of people who will functionally move to meet the organizational objectives. To enhance the effectiveness of the organization, all members of the organization should work together with effective communication and commitment. Based on the explanation above on the group cohesiveness and the relationship with work performance, , this conceptual paper need to be carried out further based on some of the variables identified through the literature This study also proposes a framework for conducting the research at the Sungai Petani Community College in Kedah, Malaysia. The conceptual framework is as below:

Group Cohesiveness Attributes

\begin{tabular}{|c|c|c|c|c|}
\hline IV & & Mod V & & DV \\
\hline $\begin{array}{l}\text { - Communication } \\
\text { - Understandable } \\
\text { Objectives } \\
\text { - Commitment }\end{array}$ & $\mathrm{H} 2$ & $\begin{array}{c}\text { Management } \\
\text { Role }\end{array}$ & $\mathrm{H} 3$ & $\begin{array}{c}\text { Work } \\
\text { Performance }\end{array}$ \\
\hline & $\mathrm{H} 1$ & & & \\
\hline
\end{tabular}




\section{Refferences:}

Alvarez, A., Butterfield, L. and Ridgeway, D. "Building Group Cohesion in the Workplace.” Clinical Psychology Associates of North Central Florida

Website, http://cpancf.com/articles files/buildinggroupcohesionintheworkplace.asp Accessed November 25, 2013.

Beal, D. J., Cohen, R. R., Burke, M. J., \& McLendon, C. L. (2003). Cohesion and performance in groups: a metaanalytic clarification of construct relations. Journal of Applied Psychology, 88, 989-1004.

http://dx.doi.org/10.1037/0021-9010.88.6.989

Bishop, J., Scott, K., and Burroughs, S. (2000). “Support, Commitment, and Employee https://www.isixsigma.com/implementation/teams/high-performance-teams-understanding- teamcohesiveness/ (en.wikipedia.org/wikipedia/group cohesiveness).

Carron, A. V., \& Brawley, L. R. (2012). Cohesion Conceptual and Measurement Issues. Small Group Research, 43(6), 726-743. http://dx.doi.org/10.1177/1046496412468072

Castaño, N., Watts, T., \& Tekleab, A. G. (2013). A reexamination of the cohesion-performance relationship metaanalyses: A comprehensive approach. Group Dynamics: Theory, Research, and Practice, 17(4), 207.http://dx.doi.org/10.1037/a0034142

Drescher, S., Burlingame, G., \& Fuhriman, A. (2012). Cohesion an odyssey in empirical understanding. Small Group Research, 43(6), 662-689. http://dx.doi.org/10.1177/1046496412468073

Greer, L. L. (2012). Group Cohesion Then and Now. Small Group Research, 43(6), 655-661. http://dx.doi.org/10.1177/1046496412461532

Lott, A. J., \& Lott, B. E. (1965). Group cohesiveness as interpersonal attraction: A review of relationships with antecedent and consequent variables. Psychological bulletin, 64, 259-309. doi:10.1037/h0022386

S.L.McShane \& M.A.Von Glinow, "Organizational Behavior", (U.S.A: Irwin McGraw-Hill, 2000)

Stephen, P.Robbins., “Organizational Behavior”, (New Jersey: Prentice Hall, 2001) 